\title{
Plasma-Activation of Larger Liquid Volumes by an Inductively-Limited Discharge for Antimicrobial Purposes
}

\author{
Michael Schmidt ${ }^{1, *}$, Veronika Hahn ${ }^{1}$, Beke Altrock ${ }^{1}$, Torsten Gerling ${ }^{1}{ }^{1}$, \\ Ioana Cristina Gerber ${ }^{2}\left(\mathbb{D}\right.$, Klaus-Dieter Weltmann ${ }^{1}$ and Thomas von Woedtke ${ }^{1,3}{ }^{\mathbb{D}}$ \\ 1 Leibniz Institute for Plasma Science and Technology, Felix-Hausdorff-Str. 2, 17489 Greifswald, Germany; \\ veronika.hahn@inp-greifswald.de (V.H.); b.c.altrock@googlemail.com (B.A.); \\ gerling@inp-greifswald.de (T.G.); weltmann@inp-greifswald.de (K.-D.W.); \\ woedtke@inp-greifswald.de (T.v.W.) \\ 2 Faculty of Physics, Alexandru Ioan Cuza University of Iasi, 700506 Iaşi, Romania; \\ cristinaioana.gerber@gmail.com \\ 3 Department of Hygiene and Environmental Medicine, Greifswald University Medicine, \\ 17475 Greifswald, Germany \\ * Correspondence: M_Schmidt@inp-greifswald.de; Tel.: +49-3834-554-3866
}

Received: 26 April 2019; Accepted: 22 May 2019; Published: 27 May 2019

\begin{abstract}
A new configuration of a discharge chamber and power source for the treatment of up to $1 \mathrm{~L}$ of liquid is presented. A leakage transformer, energizing two metal electrodes positioned above the liquid, limits the discharge current inductively by utilizing the weak magnetic coupling between the primary and secondary coils. No additional means to avoid arcing (electric short-circuiting), e.g., dielectric barriers or resistors, are needed. By using this technique, exceeding the breakdown voltage leads to the formation of transient spark discharges, producing non-thermal plasma (NTP). These discharges effected significant changes in the properties of the treated liquids (distilled water, physiological saline solution, and tap water). Considerable concentrations of nitrite and nitrate were detected after the plasma treatment. Furthermore, all tested liquids gained strong antibacterial efficacy which was shown by inactivating suspended Escherichia coli and Staphylococcus aureus. Plasma-treated tap water had the strongest effect, which is shown for the first time. Additionally, the $\mathrm{pH}$-value of tap water did not decrease during the plasma treatment, and its conductivity increased less than for the other tested liquids.
\end{abstract}

Keywords: inductively-limited discharge; plasma-treated water; tap water; antimicrobial activity

\section{Introduction}

In recent years, investigations of plasma-liquid interactions have become an important topic in plasma science and technology, not least being stimulated by the accelerating field of plasma medicine. Consequently, electrical discharges in combination with liquids have been extensively studied. Resulting from plasma-liquid interactions, very complex physical as well as chemical processes occur starting from gas phase chemistry via multiphase species transport, mass and heat transfer up to interfacial reactions and very complex liquid phase chemistry. In the case of low-temperature plasma sources working at atmospheric air conditions (cold atmospheric plasmas-CAP), this chemistry is mainly determined by reactive oxygen and nitrogen species transferred from the gas/plasma phase into the liquid phase or generated in the liquid phase by secondary reactions [1,2]. Several electrode configurations and modes of electrical operation for liquid treatment were investigated. Generally, these discharges can be ignited directly in the liquid [3], between one electrode above the liquid and 
the surface of the liquid itself serving as the counter electrode [4-6], and in close vicinity to the water surface, e.g., by a dielectric barrier discharge [7] or with a gliding arc discharge [8]. Configurations using plasma jets [9] or high-voltage-fed hollow needles [10] and electro-spraying were also investigated [11]. The discharges can be energized with DC, AC, or pulsed high voltage $[4,12,13]$.

Besides the various ways of operating these discharges, their physical properties like breakdown voltage, discharge current and morphology, gas temperature, and light emission are discussed. As liquids, different kinds of water were used (distilled water, saline solution, buffered solutions, or tap water). For comprehensive summaries of the broad variety of discharges in combination with liquids, please refer to $[1,14,15]$. Regarding the treatment of water, changes of its properties have been examined by many researchers [6-9,16-19]. In all cases of discharges operated in contact with or in close vicinity to water, acidification (except for tap water) and nitration was observed. Additionally, it was described that chemical contaminations, e.g., with pharmaceuticals, in the water were decomposed over the course of the plasma treatment [20-22]. Further experiments revealed that the plasma-treated water became antimicrobial $[5,7,18]$. In these experiments, bacteria such as Staphylococcus aureus and Escherichia coli were significantly inactivated. Several tests were performed with bacterial suspensions, i.e., the microorganisms to be inactivated were present during plasma treatment of the liquid (direct plasma treatment). However, it was also demonstrated that plasma-treated liquids show antibacterial activity if the microorganisms were added immediately after plasma treatment of the liquid (indirect plasma treatment) [18,23]. Traylor et al. [24] have shown that distilled water which was plasma treated for $20 \mathrm{~min}$ retained its antibacterial activity for 7 days. Hänsch et al. [18] discussed that the plasma-generated species hydrogen peroxide and nitrite decrease but are still present $1.5 \mathrm{~h}$ after the treatment was finished. According to the present state of knowledge, reactive oxygen and nitrogen species (ROS and RNS) play an important role in plasma-mediated inactivation of microorganisms [25]. These findings have given rise to the conclusion that plasma treatment of aqueous liquids might be useful to produce biologically-active formulations for several applications in the medical field like disinfectants or antiseptics [26,27].

Many of the aforementioned experiments were performed with rather small volumes of water, i.e., in the range of milliliters. For the characterization of the plasma itself and the antimicrobial properties, as well as the chemistry of the liquids, this volume is sufficient. To enable relevant conditions for applications using plasma-treated liquid, larger volumes are required. Therefore, we designed a discharge configuration for the activation of liquid volumes up to $1 \mathrm{~L}$. In order to ensure easy operation and handling, we used a pin-to-liquid design. The limiting of the discharge current turned out to be the most challenging part of the development, because dielectric barriers on the electrodes require very high operating voltages, whereas current limiting resistors waste too much electrical energy by heating. As a solution, we found inductive limiting of the discharge current by a choke. This resulted in the use of a leakage transformer, which will be discussed later in detail.

\section{Materials and Methods}

\subsection{Electrical and Optical Investigations}

For the investigations, two different experimental setups were designed. The experimental setup used for the assessment of the discharge parameters consisted of two electrodes made of stainless steel (diameter $4 \mathrm{~mm}$, length $32 \mathrm{~mm}$ ). These electrodes were fixed to an electrode holder and positioned about $3 \mathrm{~mm}$ above the surface of the liquid in a beaker with a volume of $250 \mathrm{~mL}$ (Figure 1). The electrode holder was a round shape disk made of polycarbonate with a diameter of $120 \mathrm{~mm}$ and a thickness of $80 \mathrm{~mm}$. The electrodes were connected to the output transformer of a commercial high-voltage source (Neon-Pro NP 10000-30) operating the discharge at a frequency of approximately $25 \mathrm{kHz}$ and ignition voltages of about $2-3 \mathrm{kV}$ (amplitude). The high voltage source was driven by a variac (RFT LTS 002) connected directly to the net. Details of the electrical parameters are given in the electrical characterization section. 


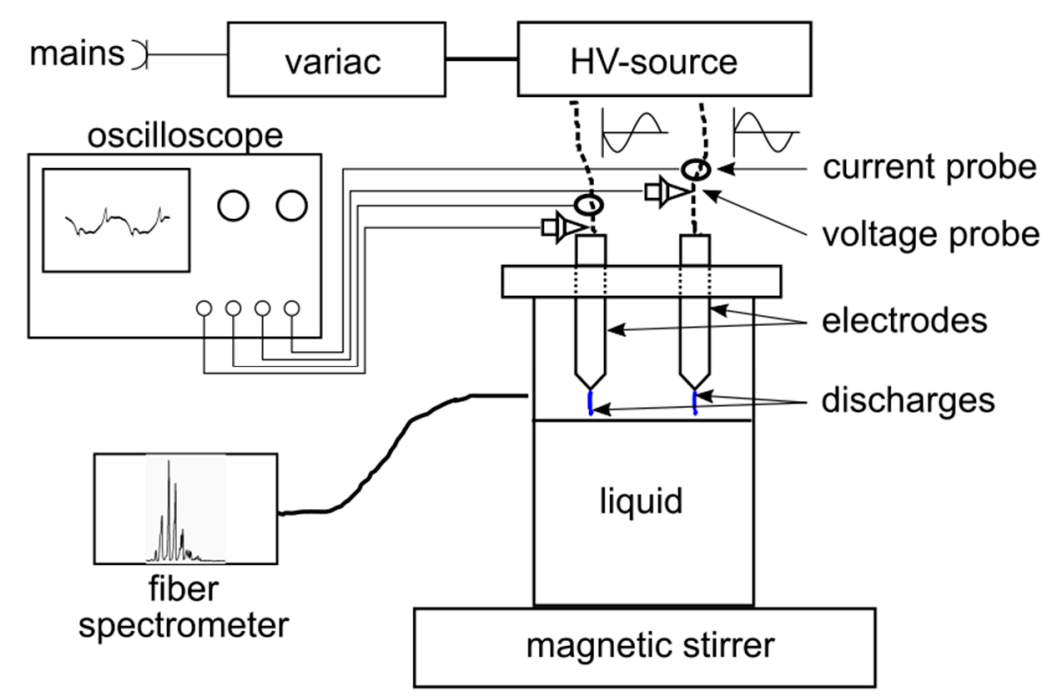

Figure 1. Experimental setup.

The beaker with the electrode holder was placed on a magnetic stirrer (Thermo Scientific Cimarec i Mono) and the water was stirred permanently. The electrical data were monitored with high voltage probes (Tektronix P6015A) and current probes (Pearson 2877) and recorded with a digital oscilloscope (Tektronix DPO 4104, Tektronix, Beaverton, OR, US). The power dissipated into the high voltage source was measured by a voltage meter (PCE-PA 6000). The discharges were optically investigated with a fiber spectrometer (Ocean Optics HR4000, Ocean Optics, Largo, FL, US) via an orifice in the beaker.

For the plasma-treatment of water, the electrode configuration described above was doubled, as described in [28]. Thus, four electrodes were positioned with a holder on top of a beaker with a volume of $0.5 \mathrm{~L}$ or $1 \mathrm{~L}$. Pictures of the discharge configurations (Figure 2) were taken with a digital camera (Canon EOS 70D with a macro lens Tamron XR Di II). Tap water, physiological saline solution (distilled water with $0.85 \% \mathrm{NaCl}$ ), and distilled water were treated for up to $30 \mathrm{~min}$.

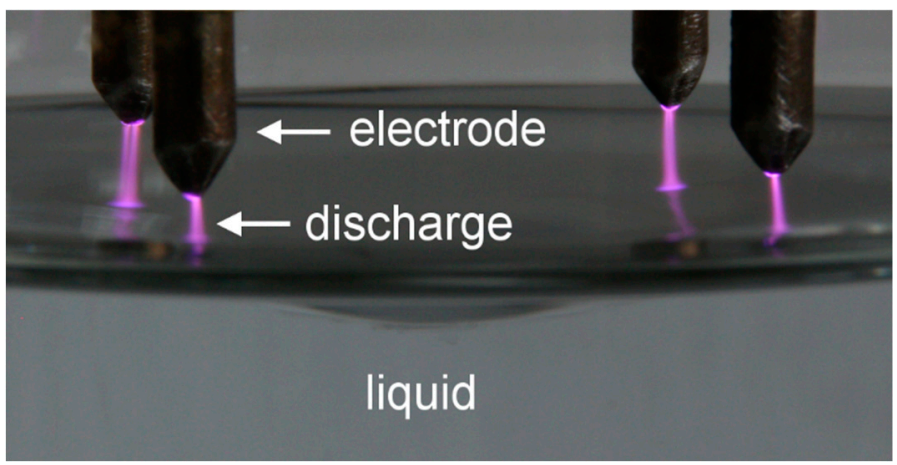

Figure 2. Photograph of the 4-electrode configuration for treatment of up to $1 \mathrm{~L}$ water [28].

\subsection{Investigation of Properties of the Treated Water}

The $\mathrm{pH}$-value, the conductivity, and the temperature were measured with a multiparameter meter (Hanna Instruments HI 9828, Vöhringen, Germany. Nitrogen species, namely nitrite and nitrate, were detected by ion chromatography using a Dionex ICS 5000 system (Thermo Scientific, Dreieich, Germany) with a UV and conductivity detector. The system was controlled by Dionex Chromeleon Version 7.1.2.1541. Separation of substances was performed via an anion-exchange column $(6 \mu \mathrm{m}$, $2 \times 250 \mathrm{~mm}$, Dionex IonPac AS23, Thermo Scientific) with a guard column $\left(0.25 \mathrm{~mL} \mathrm{~min}^{-1}\right.$, Dionex IonPac AG23, Thermo Scientific). An eluent concentrate (Dionex AS23, Thermo Scientific) was diluted to produce a solvent system of $4.5 \mathrm{mM}$ sodium carbonate and $0.8 \mathrm{mM}$ sodium bicarbonate. Nitrite 
as well as nitrate were detected at $210 \mathrm{~nm}$. Identification and quantification was performed with reference substances (sodium nitrite and sodium nitrate, purity $\geq 99 \%$, Carl Roth GmbH \& Co. KG). The amount of hydrogen peroxide $\left(\mathrm{H}_{2} \mathrm{O}_{2}\right)$ generated in the plasma-treated water was measured spectrophotometrically at $405 \mathrm{~nm}$ (UV-3100PC, VWR International, Hannover, Germany) after reaction with titanium sulfate.

\subsection{Microorganisms and Culture Conditions}

The bacteria Staphylococcus aureus DSM 799/ATCC 6538 (DSM-German Collection of Microorganisms and Cell Cultures, ATCC-American Type Culture Collection) and Escherichia coli K-12 DSM 11250/NCTC 10538 (NCTC-National Collection of Type Cultures) were cultured on tryptic soy agar plates (Carl Roth GmbH \& Co. KG, Karlsruhe, Germany). After an incubation of $24 \mathrm{~h}$ at $37^{\circ} \mathrm{C}$ the agar plates were stored at $8{ }^{\circ} \mathrm{C}$.

For the experiments, the respective microorganism was cultured in $20 \mathrm{~mL}$ tryptic soy broth (Carl Roth $\mathrm{GmbH} \& \mathrm{Co} . \mathrm{KG}$, Karlsruhe, Germany). After an incubation time of $24 \mathrm{~h}$ at $37^{\circ} \mathrm{C}, 10 \mathrm{~mL}$ of the culture was centrifuged (4700 rpm; Heraeus Multifuge 1S, Thermo Fisher Scientific) for 5 min. The supernatant was discarded and the cells were suspended in $10 \mathrm{~mL}$ physiological saline solution $(0.85 \% \mathrm{NaCl})$. The bacteria suspension was adjusted to a total viable count of $10^{6} \mathrm{cfu} / \mathrm{mL}$ (colony forming units/mL, stock suspension).

\subsection{Determination of the Antimicrobial Effect of Plasma-Treated Liquids}

The respective liquid-physiological saline solution or tap water was treated with plasma for 10 , 20 , and $30 \mathrm{~min}$, defined as treatment time $\left(t_{\text {treat }}\right)$. Afterwards, these liquids were mixed with the microorganism-S. aureus or E. coli-and incubated for 30 or $60 \mathrm{~min}$, defined as exposure time ( $\left.t_{\text {exp }}\right)$. For this purpose, $100 \mu \mathrm{L}$ of the bacteria stock suspension was added to $5 \mathrm{~mL}$ of the plasma-treated liquid filled in a petri dish $55 \times 14.2 \mathrm{~mm}$ (VWR, Darmstadt, Germany). The liquid was incubated on a multi-functional orbital shaker (PSU-20i, biosan, Riga, Latvia) for up to 30 or $60 \mathrm{~min}$. Over the course of the exposure time, samples were taken in regular intervals and used to determine the total viable count as colony forming units $/ \mathrm{mL}$. The spiral plate method (spiral plater: Eddy Jet 2, IUL, Barcelona, Spain [29]) was used, with tryptic soy agar plates which were incubated for $24 \mathrm{~h}$ at $37^{\circ} \mathrm{C}$. The total viable count was measured by an automated colony counter (Flash \& Go, IUL, Barcelona, Spain). As a control, $100 \mu \mathrm{L}$ of the microorganism suspension was added to $5 \mathrm{~mL}$ of untreated liquid. This mixture was also used for the determination of the total viable count. All measurements were performed 6 times $(n=6)$.

The reduction of the total viable count is expressed as $\log _{10}\left(N_{R}\right)$ which was calculated as $\log _{10}\left(N_{R}\right)$ $=\log _{10}\left(N_{0}\right)-\log _{10}\left(N_{\mathrm{S}}\right)$, where $N_{0}$ is the total viable count of the control and $N_{\mathrm{S}}$ is the total viable count after the respective exposure time.

\section{Results and Discussion}

\subsection{Electrical Characterization of the Discharge}

To ignite a plasma between the metal electrodes and the surface of the liquid, we used a commercially available high voltage source usually used to operate gas discharge lamps [30]. This device provides two outputs with sinusoidal high voltages. As depicted in Figures 1 and 3, these voltages are phase-inverted to each other, meaning that the voltage on one electrode increases whereas the voltage on the other electrode decreases and vice versa. This leads to a sufficient potential difference between one electrode and the other with the liquid and the gas gaps in between. The discharge configuration could also work with grounded liquid, but this was not necessary in our configuration. Typical voltage and current waveforms for the two-electrode configuration with tap water as the liquid are shown in Figure 3. When the discharge occurs, the voltages at the electrodes (black and grey lines) collapse and the current (red and green lines) flows for some tens of nanoseconds. In these 
commercially available devices, high voltage is provided by use of leakage transformers to ensure short-circuit resistance. This means that the magnetic coupling between the primary and the secondary coil of the high-voltage transformer is weak, and thus, the output voltage collapses when the output is loaded and, consequently, the output current is limited. No additional current limiters like dielectric barriers or resistors are needed.

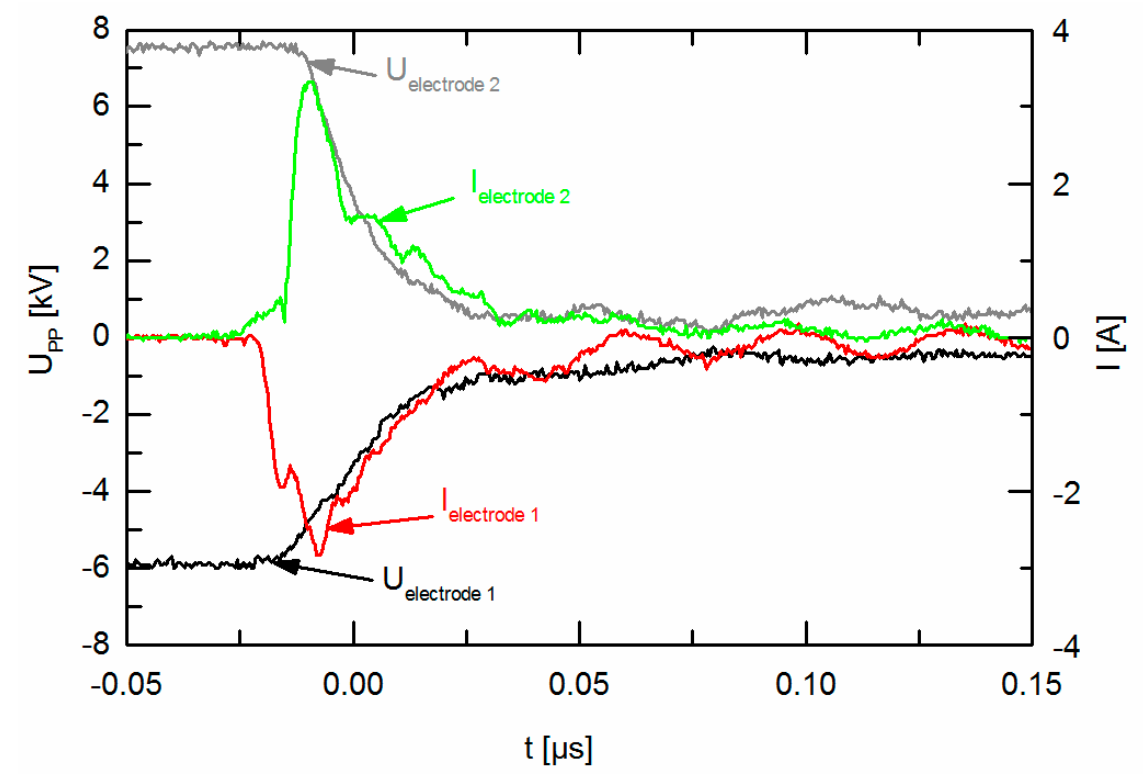

Figure 3. Electrical characterization of one discharge event with tap water as liquid [30]: Driving voltage at the electrodes (black and grey lines) and discharge current (red and green lines), discharges take place at both electrodes simultaneously.

In Figure 4, the influence of the liquid on the electrical parameters of the discharge is shown. For clearance, only the data for one electrode are presented. Generally, discharges occur very erratically, with varying breakdown voltage and different numbers of discharges per period. The presented waveforms are the most common. It was determined that for tap water (conductivity $\sigma=0.648 \mathrm{mS} / \mathrm{cm}$ ) and saline solution $(\sigma=16.23 \mathrm{mS} / \mathrm{cm})$ the voltage drop and the discharge current was significantly higher than for distilled water $(\sigma=0.013 \mathrm{mS} / \mathrm{cm})$. The higher discharge current was the result of the higher initial conductivity of tap water and saline solution compared to distilled water (Figure 7). It also means a higher electrical load of the secondary coil of the output transformer, resulting in a higher magnetic stray flux, leading to a lower output voltage.

The significant influence of the conductivity of the liquid was also studied by Bruggeman et al. [31]. There, it was shown that a conductivity of $0.5-1 \mathrm{mS} / \mathrm{cm}$ leads to the highest current compared to larger and smaller conductivities. This was also confirmed in our experiments with the highest current using tap water $(\sigma=0.648 \mathrm{mS} / \mathrm{cm})$.

Because of the erratic behavior of the discharges, the electrical power dissipated into the plasma was difficult to quantify. For a preliminary assessment of the efficiency of the process, the plug power (in this case the power dissipated into the high voltage source) was measured by a commercially available power meter. It was less than $50 \mathrm{~W}$ for the 4-electrode configuration, regardless of the treated liquid. This resulted in the consumption of less than $50 \mathrm{Wh}$ for the production of $1 \mathrm{~L}$ plasma-treated water (equaling an expense of presently $\approx 0.02 €$ per liter for electricity and water). 
a)

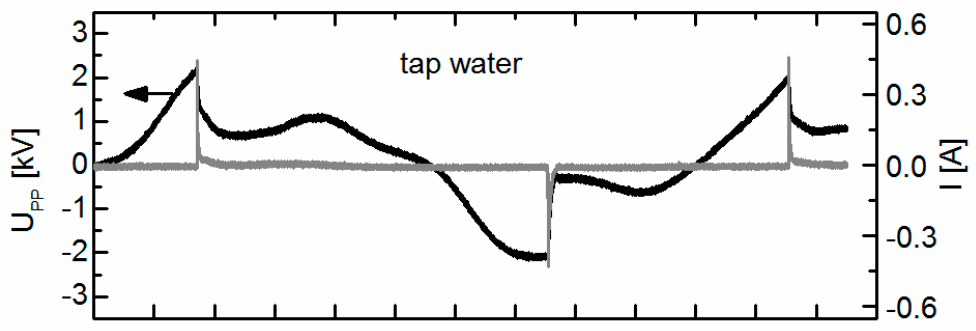

b)

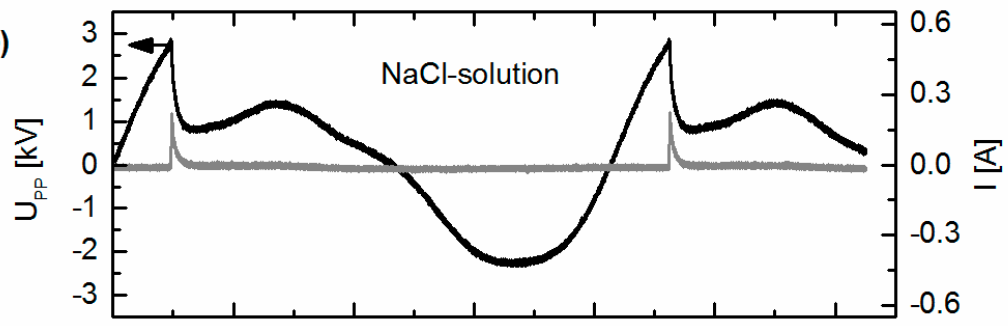

c)

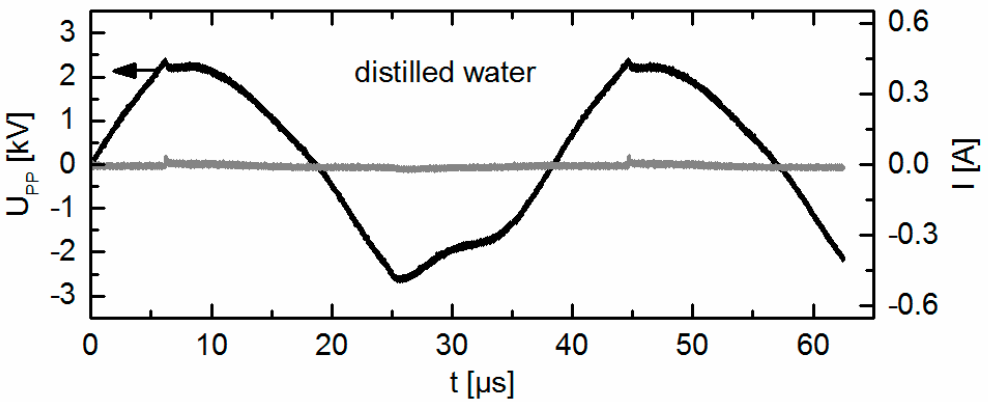

Figure 4. Electrical characterization for different treated liquids measured on one electrode: (a) tap water $\sigma=0.648 \mathrm{mS} / \mathrm{cm}$, (b) saline solution $\sigma=16.23 \mathrm{mS} / \mathrm{cm}$, (c) distilled water $\sigma=0.013 \mathrm{mS} / \mathrm{cm}$.

\subsection{Optical Characterization of the Discharge}

It was visible with the naked eye that the color of the discharge was dependent on the treated liquid. The typical bluish/pinkish color of a non-thermal plasma operated in air changed to greenish when saline solution was treated instead of distilled water or tap water. The assumption that this was attributed to the emission of sodium was verified by optical emission spectroscopy (Figure 5). Significant emission of the Na-D-line at $589 \mathrm{~nm}$ (for the performed investigation it was not necessary to resolve the sodium doublet) was detected in the case of saline solution as the liquid. Although the nitrogen $\left(\mathrm{N}_{2}\right)$ emissions dominated the spectra, for tap water and saline solution, small emissions of nitrogen monoxide (NO) were also detected. Additionally, it was clearly shown that in the case of distilled water the general emission intensity was the lowest in good agreement with the lowest discharge current.

\subsection{Chemical Characterization of the Liquids}

Many researchers report strong acidification of the liquid by plasma treatment as long as non-buffered solutions are used $[5,18]$. The presence of a phosphate buffer inhibits the acidification $[7,32]$. Depending on the treated volume and the plasma source used, the acidification takes only one minute $(\mathrm{V}=1.5 \mathrm{~mL}$, [7]) or more than $10 \mathrm{~min}(\mathrm{~V}=1 \mathrm{~L}$, [5]). We treated in our experiments $500 \mathrm{~mL}$ of water for $30 \mathrm{~min}$ and opted for $10 \mathrm{~min}$ interval of measurement to investigate the general behavior of the liquid (Figures 6 and 7). In the slightly acidic $(\mathrm{pH}=5.1)$ saline solution and demineralized water $(\mathrm{pH}=4.8)$, the $\mathrm{pH}$-value decreased to about 3 within 10 min treatment time whereas tap water $(\mathrm{pH}=6.6)$ was not acidified at all. To our knowledge, this is due to the sufficient amount of buffering components like carbonate which corresponds to the high hardness of the local water used in this study $\left(23.3^{\circ} \mathrm{dH}\right.$ [33] compared to an average of $16^{\circ} \mathrm{dH}$ in Germany [34]). 


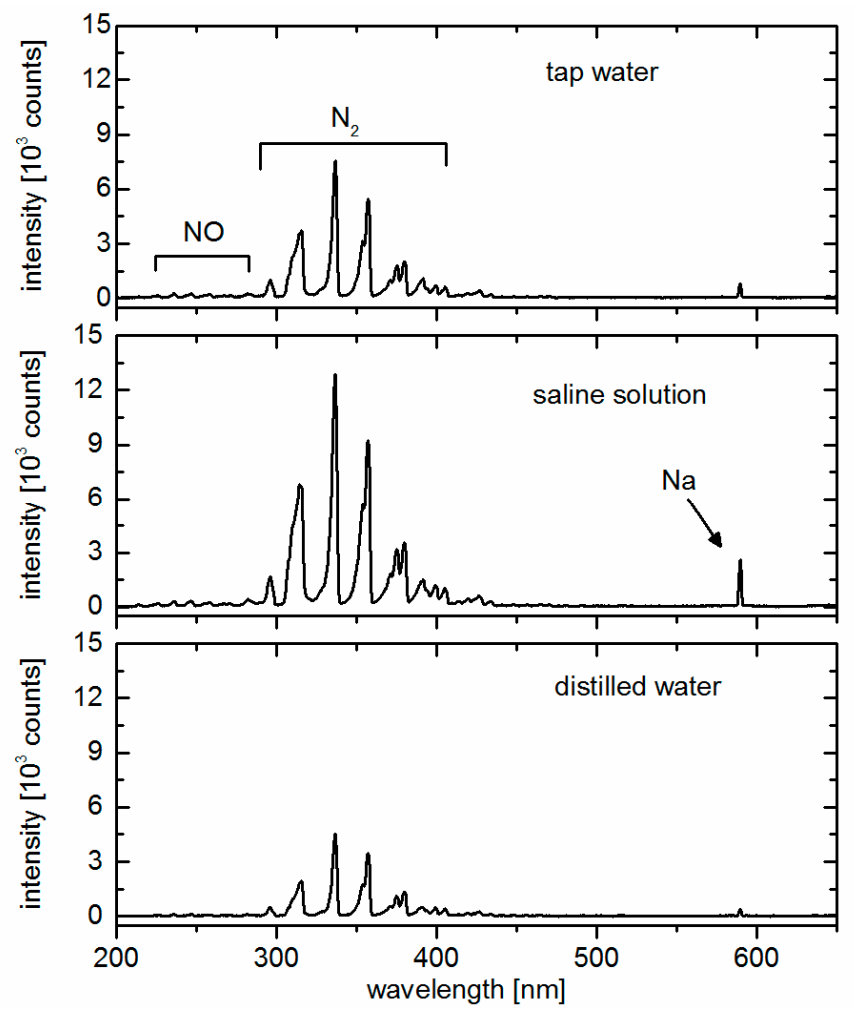

Figure 5. Optical characterization of the discharge for different liquids, the Na-D line is almost missing for liquids not containing sodium.

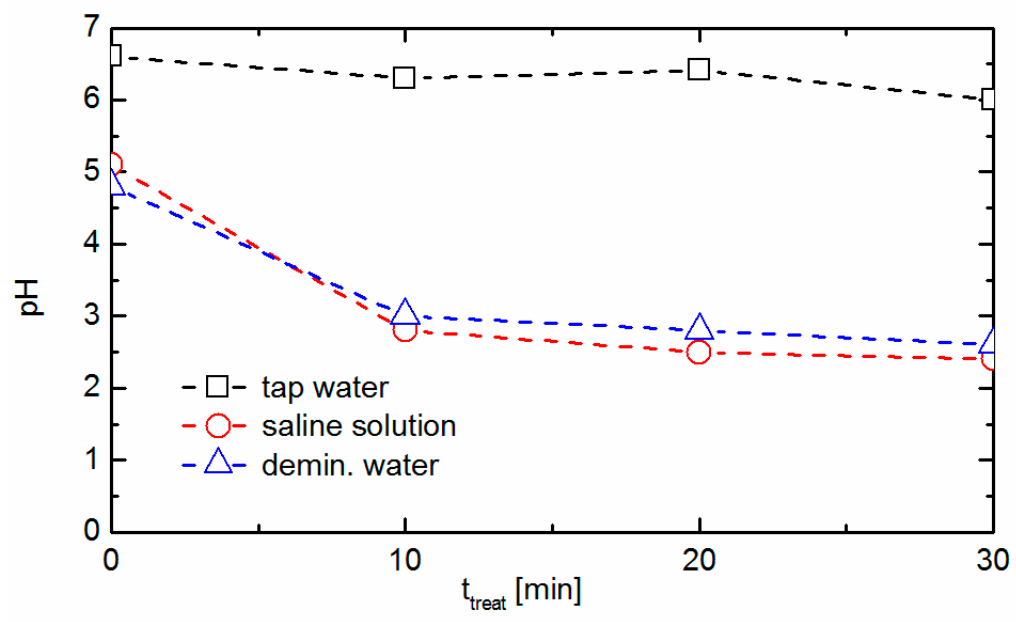

Figure 6. Change of $\mathrm{pH}$-value with treatment time.

Figure 7 shows the change of the conductivity $\sigma$ of the tested liquids. It was determined that the conductivity of the almost non-conductive distilled water increased significantly by around $300 \mu \mathrm{S} / \mathrm{cm}$, which was in the range of the values reported in [4] $(\Delta \sigma=150 \mu \mathrm{S} / \mathrm{cm}$ in $10 \mathrm{~min})$. Also, for saline solution with a very high initial conductivity, an increase of about $700 \mu \mathrm{S} / \mathrm{cm}$ was measured. Again, we found different results for tap water. The increase in conductivity was less than $50 \mu \mathrm{S} / \mathrm{cm}$ after 30 min treatment.

After $t_{\text {treat }}=30 \mathrm{~min}$, the concentrations of $\mathrm{NO}_{2}{ }^{-}$and $\mathrm{NO}_{3}{ }^{-}$were $1.55 \mathrm{mM}$ and $0.77 \mathrm{mM}$, respectively (data not shown). Contrary to many other reported experiments, the concentration of $\mathrm{H}_{2} \mathrm{O}_{2}$ was negligible [6-8,32]. The optical emission spectra (Figure 5) show significant emissions of nitrogen and also emissions of nitrogen monoxide. This indicates that the nitration of the liquids is caused by the input of nitrogen species into the liquid by the discharge itself. Sivachandiran and Khacef [35] reported 
positive effects on germination and growth of plants such as radish, tomato, and sweet pepper with plasma treated water containing approximately $0.26 \mathrm{mM}$ of $\mathrm{NO}_{3}{ }^{-}$. Thus, this kind of application could be an interesting field of research regarding a possible utilization of plasma treated water in agriculture. The temperature of the liquids increased slightly with a rate of $\Delta \mathrm{T} \approx 0.7 \mathrm{~K} / \mathrm{min}$. Therefore, also $30 \mathrm{~min}$ treatment does not cause notable evaporation of the liquid.

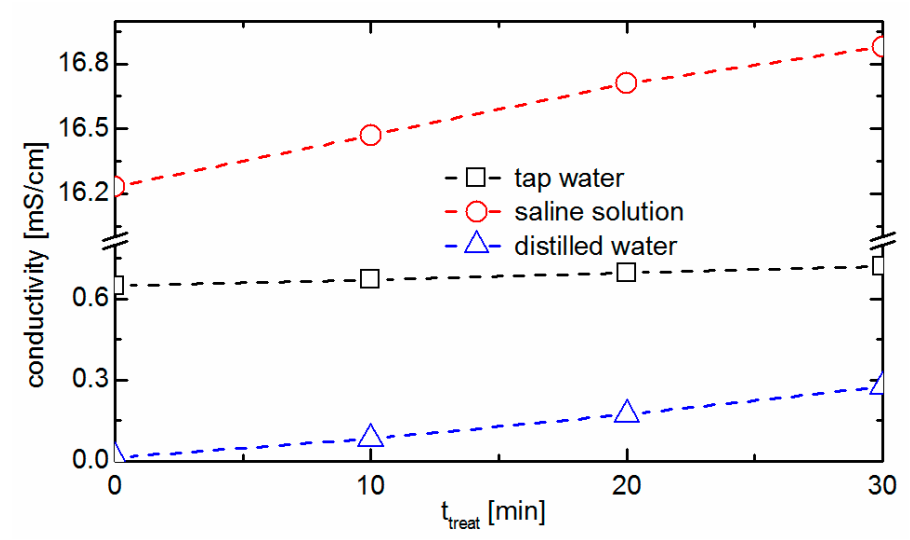

Figure 7. Change of conductivity with treatment time.

\subsection{Antimicrobial Properties of the Plasma-Treated Liquids}

In order to investigate the antimicrobial effect, a benchmark test was performed with plasma-treated physiological saline solution and the gram-negative bacterium E. coli K-12 DSM 11250/NCTC 10538. During the experimental procedure, the liquid was treated with plasma for 10, 20, or $30 \mathrm{~min}$. The microorganisms were exposed to the plasma-treated liquid for up to 30 or $60 \mathrm{~min}$ (Figure 8; data for $60 \mathrm{~min}$ not shown).

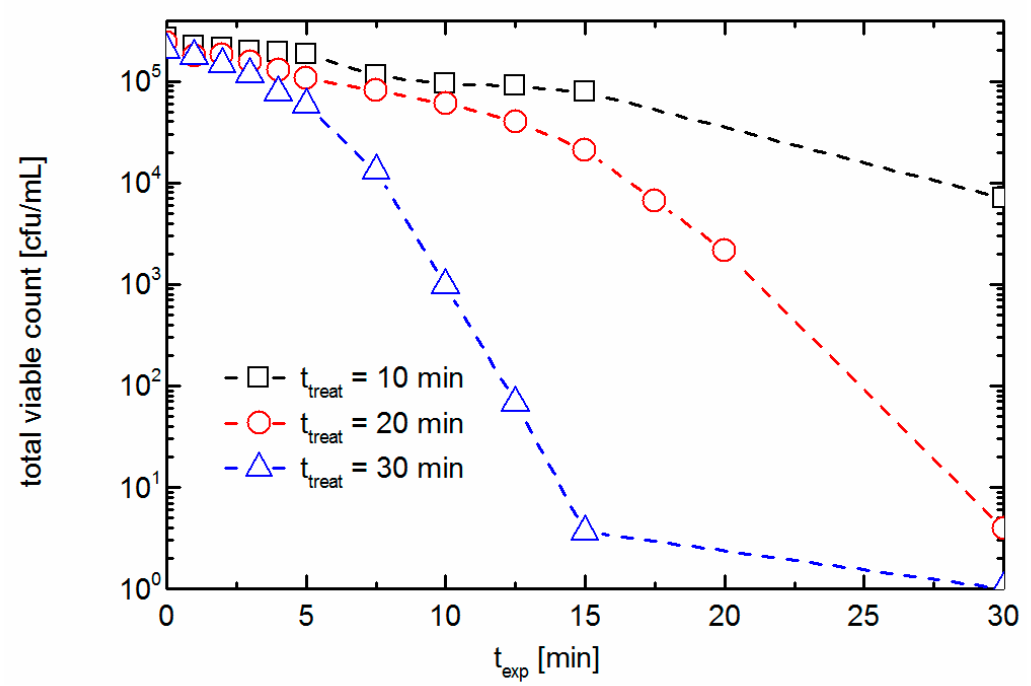

Figure 8. Antimicrobial effect of plasma-treated saline solution on the gram-negative bacterium E. coli for different treatment times: $t_{\text {treat }}=10,20$, and $30 \mathrm{~min}$, determined by total viable count $[\mathrm{cfu} / \mathrm{mL}]$ within an exposure time $t_{\exp }=30 \mathrm{~min}$.

The exposure of the microorganism E. coli to physiological saline solution treated with plasma for 10,20 or $30 \mathrm{~min}$ resulted in a reduction of 5.3 orders of magnitude $\left(\log _{10} \mathrm{cfu} / \mathrm{mL}\right)$ within $\mathrm{t}_{\exp }=$ 30-60 min. The inactivation of E. coli was dependent on the treatment time. Thus, within an exposure time of $10 \mathrm{~min}$ a reduction of total viable cell count of 0.5 orders of magnitude was determined for $t_{\text {treat }}=10$ min whereas for $t_{\text {treat }}=30$ min already a reduction of 2.3 orders of magnitude was reached. The fastest inactivation for E. coli occurred with the $30 \mathrm{~min}$ plasma-treated saline solution. For this 
treatment time, no microorganisms were detected after $t_{\exp }=30 \mathrm{~min}$ and for $t_{\text {treat }}=20 \mathrm{~min}$, the residual viable count was negligible $(3.9 \mathrm{cfu} / \mathrm{mL}$ ) after the same exposure time (Figure 8). Moreover, a prolongation of $t_{\exp }$ to $60 \mathrm{~min}$ resulted also for $t_{\text {treat }}=10 \mathrm{~min}$ in complete inactivation of tested microorganisms (data not shown). Thus, the antimicrobial effect of the plasma-treated liquid was dependent on the treatment time and the exposure time. The inactivation of the microorganisms was faster with longer treatment time or exposure time. These two factors can be used for the regulation of the antimicrobial activity. This correlation of treatment time and antimicrobial activity has been shown previously for other plasma sources [18,36,37].

The results of the benchmark test showed that the antimicrobial effect of the plasma-treated saline solution was strong enough to inactivate successfully E. coli in all experiments performed. The antimicrobial properties of plasma-treated water like deionized or sterilized water have already been shown by Liu et al. [9] and Lukes et al. [17]. Thus, we investigated the antimicrobial effect of tap water, which differed in the important fact that it shows no decrease of the $\mathrm{pH}$-value due to plasma treatment (Figure 6). Again, the microorganism E. coli was used. Additional experiments were performed with the gram-positive bacterium S. aureus. The results of the experiments with tap water were compared with those of plasma-treated saline solution. Since the liquid treated for $30 \mathrm{~min}$ showed the strongest antimicrobial effect we decided to use $t_{\text {treat }}=30 \mathrm{~min}$ in all experiments.

The reductions of the total viable count of E. coli and S. aureus in plasma-treated tap water were more than 5 orders of magnitude (Figure 9). In general, it was found that the level as well the kinetics of inactivation of the microorganisms was dependent on the kind of plasma-treated liquid. Thus, the inactivation by 5 orders of magnitude was achieved for $E$. coli in saline solution after $t_{\exp }=15$ min whereas for tap water already $t_{\exp }=5 \mathrm{~min}$ resulted in the same reduction. In the case of S. aureus, after $t_{\exp }=30 \mathrm{~min}$, the reduction was approximately 3 orders of magnitude in plasma-treated saline solution but again 5 orders of magnitude for plasma-treated tap water. The plasma-treated tap water was much more effective against the tested microorganisms E. coli and S. aureus than saline solution. This confirms that using this pin-to-liquid plasma device the plasma-treatment of tap water delivers a liquid which has a stronger antimicrobial effect than plasma-treated saline solution.

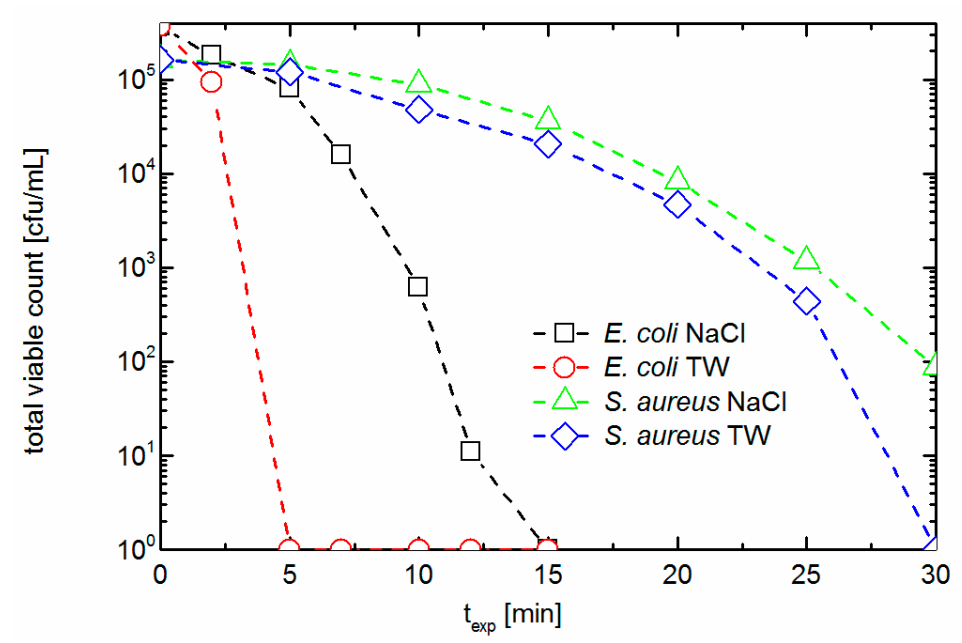

Figure 9. Antimicrobial effect of plasma-treated saline solution $(\mathrm{NaCl})$ on E. coli (boxes) and S. aureus (triangles) as well as plasma-treated tap water (TW) on E. coli (circles) and S. aureus (rhombi), $\mathrm{t}_{\text {treat }}=30 \mathrm{~min}$.

In general, non-buffered aqueous systems such as saline solution are characterized by a decrease of the $\mathrm{pH}$-value in course of the plasma treatment. It was assumed that $\mathrm{pH}$-decrease has an indirect influence on the antimicrobial activity of the plasma-treated liquid [7]. The decrease of the $\mathrm{pH}$-value is hypothesized to be caused by the dissociation of nitric oxides in water. The resulting formation of reactive oxygen and nitrogen species (ROS/RNS) indicated by nitrite and nitrate generation leads to the antimicrobial effect. Thus, the acidic $\mathrm{pH}$ plays a rather subordinate role [11,38]. Such an indirect 
influence of the $\mathrm{pH}$-value in saline solution cannot be assumed for tap water because the $\mathrm{pH}$ remains constant. The origin of the antimicrobial effect in tap water despite constant $\mathrm{pH}$ is rather unclear, but Marotta et al. described experiments with a DBD regarding the degradation of phenol in plasma-treated deionized and tap water [39]. In these tests, it was confirmed that tap water has a higher degradation efficiency because of the presence of sodium bicarbonate $\left(\mathrm{NaHCO}_{3}\right)$. Sodium bicarbonate maintains the $\mathrm{pH}$-value of the liquid and is a quencher for $\mathrm{OH}$ radicals, which is an unwanted effect; however, it leads also to the formation of the $\mathrm{CO}_{3}{ }^{-\bullet}$ anion, which oxidizes organic compounds efficiently [39]. Thus, we assume that sodium bicarbonate may also play an important role for antibacterial activity of plasma-treated tap water.

The plasma-treatment of tap water resulted in antimicrobial properties which are even stronger than achieved for saline solution. This is very promising because tap water is easy available and inexpensive. No additional means are necessary for decontamination. Thus, deionization or the addition of sodium chloride is not required to generate water with antimicrobial properties. But it is important to note that the chemical composition of tap water strongly depends on the area of use. Therefore, more comprehensive investigations are needed.

\section{Conclusions and Outlook}

A new configuration of discharge chamber and power source was presented utilizing high voltage leakage transformers for discharge current limitation to avoid arcing. The electrical operation of discharges between metal electrodes and a liquid was discussed. It was found that the conductivity of the liquid influenced the discharge current and voltage at breakdown. The kind of liquid influenced the optical appearance of the discharge. Sodium emissions were present in the spectra recorded with saline solution but were almost absent for distilled water and tap water. Except for tap water, the treated liquids became acidic and the conductivity increased. In all liquids, distinct nitrification was observed. The microbiological studies showed that physiological saline solution and tap water became antimicrobial, which is especially noteworthy for the case of tap water. Despite the lack of acidification, an inactivation of the tested microorganisms E. coli and S. aureus was determined.

In order to obtain more detailed insight in the discharge process itself, additional investigations are needed. To clarify the origin of the antimicrobial properties of tap water, measurements regarding the production of reactive oxygen and nitrogen species (ROS/RNS) and an evaluation of the influence of sodium bicarbonate are necessary.

With the presented discharge configuration, significant volumes of plasma-treated water can be easily produced in less than $30 \mathrm{~min}$. Because the device is portable, the water can be treated on-site. The properties of the treated water are controllable by setting the treatment time. The antimicrobial effect of the plasma-treated water can be adjusted by varying the exposure time. Thus, the discharge configuration is an appropriate experimental setup for the investigation of practical applications of plasma-treated water. Besides its use as a disinfecting agent, application as a fertilizer with additional disinfecting properties in agriculture is also conceivable. Additionally, the use of the plasma device for cleaning of contaminated water should be considered.

Author Contributions: Conceptualization, M.S.; Formal analysis, M.S., B.A. and I.C.G.; Funding acquisition, K.-D.W. and T.v.W.; Investigation, M.S., V.H., B.A. and T.G.; Methodology, M.S., V.H., B.A. and T.G.; Project administration, M.S., V.H. and T.G.; Resources, M.S., V.H. and T.G.; Supervision, K.-D.W. and T.v.W.; Writing-original draft, M.S., V.H., B.A. and I.C.G.; Writing—review \& editing, M.S., V.H., T.G., K.-D.W. and T.v.W.

Funding: This work was funded by the German Ministry of Education and Research (BMBF, grant 13N13960) and by the Ministry of Education, Science and Culture of the State of Mecklenburg-Vorpommern (grant: AU 15 001), which is gratefully acknowledged.

Acknowledgments: The authors like to thank Ronny Brandenburg, Hans Höft, Philipp Turski, and Kristin Loyal for fruitful discussions and laboratory assistance.

Conflicts of Interest: The authors declare no conflict of interest. The funders had no role in the design of the study; in the collection, analyses, or interpretation of data; in the writing of the manuscript, or in the decision to publish the results. 


\section{References}

1. Bruggeman, P.J.; Kushner, M.J.; Locke, B.R.; Gardeniers, J.G.; Graham, W.G.; Graves, D.B.; Hofman-Caris, R.C.H.M.; Maric, D.; Reid, J.P.; Ceriani, E.; et al. Plasma-liquid interactions: A review and roadmap. Plasma Sources Sci. Technol. 2016, 25, 053002. [CrossRef]

2. Vanraes, P.; Bogaerts, A. Plasma physics of liquids-A focused review. Appl. Phys. Rev. 2018, 5, 031103. [CrossRef]

3. Kolb, J.F.; Joshi, R.P.; Xiao, S.; Schoenbach, K.H. Streamer in water and other dielectric liquids. J. Phys. D Appl. Phys. 2008, 41, 234007. [CrossRef]

4. Bruggeman, P.; Ribezl, E.; Maslani, A.; Degroote, J.; Malesevic, A.; Rego, R.; Vierendeels, J.; Leys, C. Characteristics of atmospheric pressure air discharges with a liquid cathode and a metal anode. Plasma Sources Sci. Technol. 2008, 17, 025012. [CrossRef]

5. Chen, C.W.; Lee, H.-M.; Chang, M.B. Inactivation of Aquatic Microorganisms by Low-Frequency AC Discharges. IEEE Trans. Plasma Sci. 2008, 36, 215-219. [CrossRef]

6. Kovačević, V.V.; Dojčinović, B.P.; Jović, M.; Roglić, G.M.; Obradović, B.M.; Kuraica, M.M. Measurement of reactive species generated by dielectric barrier discharge in direct contact with water in different atmospheres. J. Phys. D Appl. Phys. 2017, 50, 155205. [CrossRef]

7. Oehmigen, K.; Hähnel, M.; Brandenburg, R.; Wilke, C.; Weltmann, K.-D.; von Woedtke, T. The Role of Acidification for Antimicrobial Activity of Atmospheric Pressure Plasma in Liquids. Plasma Process. Polym. 2010, 7, 250-257. [CrossRef]

8. Burlica, R.; Kirkpatrick, M.J.; Locke, B. Formation of reactive species in gliding arc discharges with liquid water. J. Electrostat. 2006, 64, 35-43. [CrossRef]

9. Liu, F.; Sun, P.; Bai, N.; Tian, Y.; Zhou, H.; Wei, S.; Zhou, Y.; Zhang, J.; Zhu, W.; Becker, K.; Fang, J. Inactivation of Bacteria in an Aqueous Environment by a Direct-Current, Cold-Atmospheric-Pressure Air Plasma Microjet. Plasma Process. Polym. 2010, 7, 231-236. [CrossRef]

10. Magureanu, M.; Mandache, N.B.; Parvulescu, V.I. Degradation of organic dyes in water by electrical discharges. Plasma Chem. Plasma Process. 2007, 27, 589-598. [CrossRef]

11. Machala, Z.; Chládeková, L.; Pelach, M. Plasma agents in bio-decontamination by dc discharges in atmospheric air. J. Phys. D Appl. Phys. 2010, 43, 222001. [CrossRef]

12. Lu, X.P.; Laroussi, M. Ignition phase and steady-state structures of a non-thermal air plasma. J. Phys. D Appl. Phys. 2003, 36, 661-665. [CrossRef]

13. Satoh, K.; MacGregor, S.J.; Anderson, J.G.; Woolsey, G.A.; Fouracre, R.A. Pulsed-Plasma Disinfection of Water Containing Escherichia coli. Jpn. J. Appl. Phys. 2007, 46, 1137-1141. [CrossRef]

14. Bruggeman, P.; Leys, C. Non-thermal plasmas in and in contact with liquids. J. Phys. D Appl. Phys. 2009, 42, 053001. [CrossRef]

15. Pawłat, J. Electrical Discharges in Humid Environments: Generators, Effects, Application; Lublin University of Technology: Lublin, Poland, 2013.

16. Kojtari, A.; Ercan, U.E.; Smith, J.; Friedman, G.; Sensenig, R.B.; Tyagi, S.; Joshi, S.G.; Ji, H.-F.; Brooks, A.D. Chemistry for Antimicrobial Properties of Water Treated with non-equilibrium plasma. J. Nanomed. Biother. Discov. 2013, 4, 120. [CrossRef]

17. Lukes, P.; Dolezalova, E.; Sisrova, I.; Clupek, M. Aqueous-phase chemistry and bactericidal effects from an air discharge plasma in contact with water: Evidence for the formation of peroxynitrite through a pseudo-second-order postdischarge reaction of $\mathrm{H}_{2} \mathrm{O}_{2}$ and $\mathrm{HNO}_{2}$. Plasma Sources Sci. Technol. 2014, 23, 015019. [CrossRef]

18. Hänsch, M.A.C.; Mann, M.; Weltmann, K.-D.; von Woedtke, T. Analysis for antibacterial efficacy of plasma-treated sodium chloride solutions. J. Phys. D Appl. Phys. 2015, 48, 454001. [CrossRef]

19. Trizio, I.; Sardella, E.; Francioso, E.; Dilecce, G.; Rizzi, V.; Cosma, P.; Schmidt, M.; Hänsch, M.; von Woedtke, T.; Favia, P.; et al. Investigation of air-DBD effects on biological liquids for in vitro studies on eukaryotic cells. Clin. Plasma Med. 2015, 3, 62-71. [CrossRef]

20. Wang, B. A Novel Dielectric-Barrier-Discharge Loop Reactor for Cyanide Water Treatment. Plasma Chem. Plasma Process. 2017, 37, 1121-1131. [CrossRef] 
21. Banaschik, R.; Lukes, P.; Jablonowski, H.; Hammer, M.U.; Weltmann, K.-D.; Kolb, J.F. Potential of pulsed corona discharges generated in water for the degradation of persistent pharmaceutical residues. Water Res. 2015, 84, 127-135. [CrossRef]

22. Malik, M.A. Water Purification by Plasmas: Which Reactors are Most Energy Efficient? Plasma Chem. Plasma Process. 2010, 30, 21-31. [CrossRef]

23. Oehmigen, K.; Winter, J.; Hähnel, M.; Wilke, C.; Brandenburg, R.; Weltmann, K.-D.; von Woedtke, T. Estimation of Possible Mechanisms of Escherichia coli Inactivation by Plasma Treated Sodium Chloride Solution. Plasma Process. Polym. 2011, 8, 904-913. [CrossRef]

24. Traylor, M.J.; Pavlovich, M.J.; Karim, S.; Hait, P.; Sakiyama, Y.; Clark, D.D.; Graves, D.B. Long-term antibacterial efficacy of air plasma-activated water. J. Phys. D Appl. Phys. 2011, 44, 472001. [CrossRef]

25. Jablonowski, H.; von Woedtke, T. Research on plasma medicine-relevant plasma-liquid interaction: What happened in the past five years? Clin. Plasma Med. 2015, 3, 42-52. [CrossRef]

26. von Woedtke, T.; Haertel, B.; Weltmann, K.-D.; Lindequist, U. Plasma pharmacy-Physical plasma in pharmaceutical applications. Pharmazie 2013, 68, 492-498. [CrossRef]

27. Joslin, J.M.; McCall, J.R.; Bzdek, J.P.; Johnson, D.C.; Hybertson, B.M. Aqueous Plasma Pharmacy: Preparation Methods, Chemistry, and Therapeutic Applications. Plasma Med. 2016, 6, 135-177. [CrossRef]

28. Hahn, V.; Dikyol, C.; Altrock, B.; Schmidt, M.; Wende, K.; Ercan, U.K.; Weltmann, K.-D.; von Woedtke, T. Plasma-mediated inactivation of E. coli: Influence of protein on wet surface and liquid medium. Plasma Process. Polym. 2019, 16, e1800164. [CrossRef]

29. Gilchrist, J.E.; Campbell, J.E.; Donnelly, C.B.; Peeler, J.T.; Delaney, J.M. Spiral plate method for bacterial determination. Appl. Microbiol. 1973, 25, 244-252.

30. Schmidt, M.; Altrock, B.; Gerling, T.; Gerber, I.C.; Hahn, V.; Weltmann, K.-D.; von Woedtke, T. AC-driven pin-to-liquid discharge: Characterization and application. In Proceedings of the ISPC 23, Montreal, QC, Canada, 30 July-4 August 2017; Available online: https://www.ispc-conference.org/ispcproc/ispc23/190.pdf (accessed on 16 May 2019).

31. Bruggeman, P.; Guns, P.; Degroote, J.; Vierendeels, J.; Leys, C. Influence of the water surface on the glow-to-spark transition in a metal-pin-to-water electrode system. Plasma Sources Sci. Technol. 2008, 17, 045014. [CrossRef]

32. Machala, Z.; Tarabova, B.; Hensel, K.; Spetlikova, E.; Sikurova, L.; Lukes, P. Formation of ROS and RNS in Water Electro-Sprayed through Transient Spark Discharge in Air and their Bactericidal Effects. Plasma Process. Polym. 2013, 10, 649-659. [CrossRef]

33. Trinkwasseranalyse. Available online: http://www.sw-greifswald.de/Energie/Trinkwasser/ Trinkwasseranalyse (accessed on 18 March 2019).

34. Wasserhärte Verzeichnis. Available online: http://www.wasserhaerte.net/deutschland/index.html (accessed on 18 March 2019).

35. Sivachandiran, L.; Khacef, A. Enhanced seed germination and plant growth by atmospheric pressure cold air plasma: Combined effect of seed and water treatment. RSC Adv. 2017, 7, 1822-1833. [CrossRef]

36. Maisch, T.; Shimizu, T.; Li, Y.F.; Heinlin, J.; Karrer, S.; Morfill, G.; Zimmermann, J.L. Decolonisation of MRSA, S. aureus and E. coli by cold-atmospheric plasma using a porcine skin model in vitro. PLoS ONE 2012, 7, e34610. [CrossRef] [PubMed]

37. Schneider, S.; Lackmann, J.W.; Narberhaus, F.; Bandow, J.E.; Denis, B.; Benedikt, J. Separation of VUV/UV photons and reactive particles in the effluent of a $\mathrm{He} / \mathrm{O}_{2}$ atmospheric pressure plasma jet. J. Phys. D Appl. Phys. 2011, 44, 295201. [CrossRef]

38. Ercan, U.K.; Smith, J.; Ji, H.F.; Brooks, A.D.; Joshi, S.G. Chemical changes in nonthermal plasma-treated $\mathrm{N}$-acetylcysteine (NAC) solution and their contribution to bacterial inactivation. Sci. Rep. 2016, 6, 20365. [CrossRef]

39. Marotta, E.; Ceriani, E.; Schiorlin, M.; Ceretta, C.; Paradisi, C. Comparison of the rates of phenol advanced oxidation in deionized and tap water within a dielectric barrier discharge reactor. Water Res. 2012, 46, 6239-6246. [CrossRef]

(C) 2019 by the authors. Licensee MDPI, Basel, Switzerland. This article is an open access article distributed under the terms and conditions of the Creative Commons Attribution (CC BY) license (http://creativecommons.org/licenses/by/4.0/). 